\title{
METHOD FOR ASSESSMENT AND CONTROL OF AVAILABILITY OF EXECUTIVE SUBSYSTEM OF A TRANSPORTATION SYSTEM
}

\author{
Maciej Woropay \\ Air Force Institute of Technology \\ Księcia Bolesława Street 6, 01-494 Warsaw, Poland \\ tel.: +48668846228 \\ Klaudiusz Migawa \\ University of Technology and Life Sciences \\ Prof. S. Kaliskiego Street 7, 85-789 Bydgoszcz, Poland \\ tel.: +48523408424 \\ e-mail:klaudiusz.migawa@utp.edu.pl,km@karor.com.pl
}

\begin{abstract}
In this work, a method for assessment and control of availability of executive subsystem consisting of elementary subsystems of the type <driver-vehicle> has been presented. The goal of the executive subsystem is to perform the assigned transport tasks over set routes, with a given frequency, according to a set schedule. A proper accomplishment of the transport task is possible only if the required number of technical objects (transport means) is prepared to perform the assigned task in a given time. Among many significant criteria used for assessment of a transport system operation there is one of special importance that is availability of the executive subsystem to perform the assigned tasks. Availability of the executive system to perform the assigned tasks depends on availability of particular technical objects (transport means) used in the system of transportation and their number. On the basis of the above statement, it can be said that control of the executive subsystem availability can be carried out both by selecting technical objects with the required availability and matching the required number of the objects which are to be used in the system in order to ensure proper accomplishment of the transport tasks. In this work there has been discussed a method for determination of the required availability of a single object as well as the required number of technical objects indispensable to perform appropriately the assigned transport task, on the basis of the transportation system availability assessment. Availability of the transportation system is determined on the basis of a mathematical model of the operation and maintenance process of technical objects, in the studied transportation system. Exemplary results have been presented on the basis of experimental data, obtained from the tests carried out in a real operation and maintenance system of transport means.
\end{abstract}

Keywords: transport system, availability, operation and maintenance process

\section{Introduction}

The basic objective of the operation of transport systems is fulfilling the transportation needs as a result of the carrying out of transport on particular routes. In general, the transport system consists of two main subsystems: logistics and executive. In the logistics subsystem, the processes carried out are supposed to assure task-based efficiency of the used technical objects. In the executive subsystem, the direct carrying out of the transport task is performed by elementary subsystems such as operator - means of transport, linked by an appropriate structure. The effectiveness of the operation of transport system depends on the possibility of correct carrying out of the assigned transport task. One of the factors strongly influencing the possibility of correct carrying out of the transport task is the availability of the executive subsystem to carry out the task $[2,7,9]$.

The technical object (element or system) availability is the object's feature which is characteristic from the point of view of the possibility of timely obtaining or maintaining the state of efficiency (facilitating the realization of goals) [9]. The executive subsystem availability for the carrying out 
of the assigned transport task depends on many factors, such as:

- choosing the appropriate availability of the technical objects (means of transport) used in the system,

- choosing the appropriate number of technical objects (means of transport) used in the transport system as well as the structure with which they are linked,

- choosing the appropriate technical objects of high reliability and receptivity to servicing and repair,

- assuring high availability and efficiency of the logistics subsystem as a result of choosing reliable and efficient intermediate devices as well as appropriate linking structure.

In this work there has been discussed a method for determination of the required availability of a single object as well as the required number of technical objects indispensable to perform appropriately the assigned transport task. The method consists of determining and comparison of the values of the required and actual availability of the executive subsystem for the carrying out of the assigned transport task and choosing the required availability of technical objects and the required number of objects used in a transport system, so that the obtained value of actual availability of the executive subsystem is higher than the value of required availability, determined by the parameters of the transport task. The actual availability of the technical objects (transport means) was defined based on a mathematically built model of the operation and maintenance process carried out in the tested transport system.

The presented results are a result of the research conducted as part of a larger research project pertaining to the construction of a decision-making model of controlling transport system availability.

\section{Model operation and maintenance process of transport means}

The operation and maintenance process model was built on the basis of analysis of the space of states and events concerning technical objects (city buses) used in the analyzed real transport system. In result of identification of the analyzed transport system, there has been determined multistate process of technical object operation and maintenance realized within it, significant states of the process and possible transitions between these states. On this basis a graph of the operation and maintenance process state changes, has been built and presented in Fig. 1, where: $\mathrm{S}_{1}$ - awaiting the carrying out of the task at the bus depot parking space, $\mathrm{S}_{2}$ - repair at the bus depot parking space without losing a ride, $\mathrm{S}_{3}$ - carrying out of the transport task, $\mathrm{S}_{4}$ - waiting for the decision of the traffic controller after occurrence of the vehicle damage, $\mathrm{S}_{5}$ - diagnosing by the emergency service unit, $\mathrm{S}_{6}$ - repair by technical support unit without losing a ride, $\mathrm{S}_{7}$ - repair by the emergency service with losing a ride, $\mathrm{S}_{8}$ - awaiting the start of task realization after technical support repair, $\mathrm{S}_{9}$ - emergency exit, $\mathrm{S}_{10}$ - waiting for action of the maintenance subsystem, $\mathrm{S}_{11}$ - refuelling, $\mathrm{S}_{12}-$ maintenance check on the operation day, $S_{13}$ - realization of periodical servicing, $S_{14}$ - prior to repair diagnosing in the serviceability assurance subsystem, $S_{15}$ - repair in the serviceability assurance subsystem, $\mathrm{S}_{16}$ - diagnosing after the repair in the serviceability assurance subsystem.

In result of carried out analysis of assumptions and restrictions, Markov's process $X(t)$ was assumed to be the model operation and maintenance process of technical objects. Using Markov's process for the operation and maintenance process mathematical modelling, the following assumptions have been accepted:

- Markov's process $X(t)$ reflects the modelled real process properly enough from the point of view of the tests,

- the modelled process of operation and maintenance has a finite number of states $S_{i}, i=1,2, \ldots, 16$,

- random process $X(t)$ which is a mathematical model of operation and maintenance process is a homogenous process,

- in time $t=0$ the process is in state $S_{1}\left(S_{1}\right.$ is the initial state).

On the basis of directed graph, presented in Fig. 1, there was built a matrix of $P$ states change probabilities and matrix of $\Lambda$ states change intensity of $X(t)$ process: 


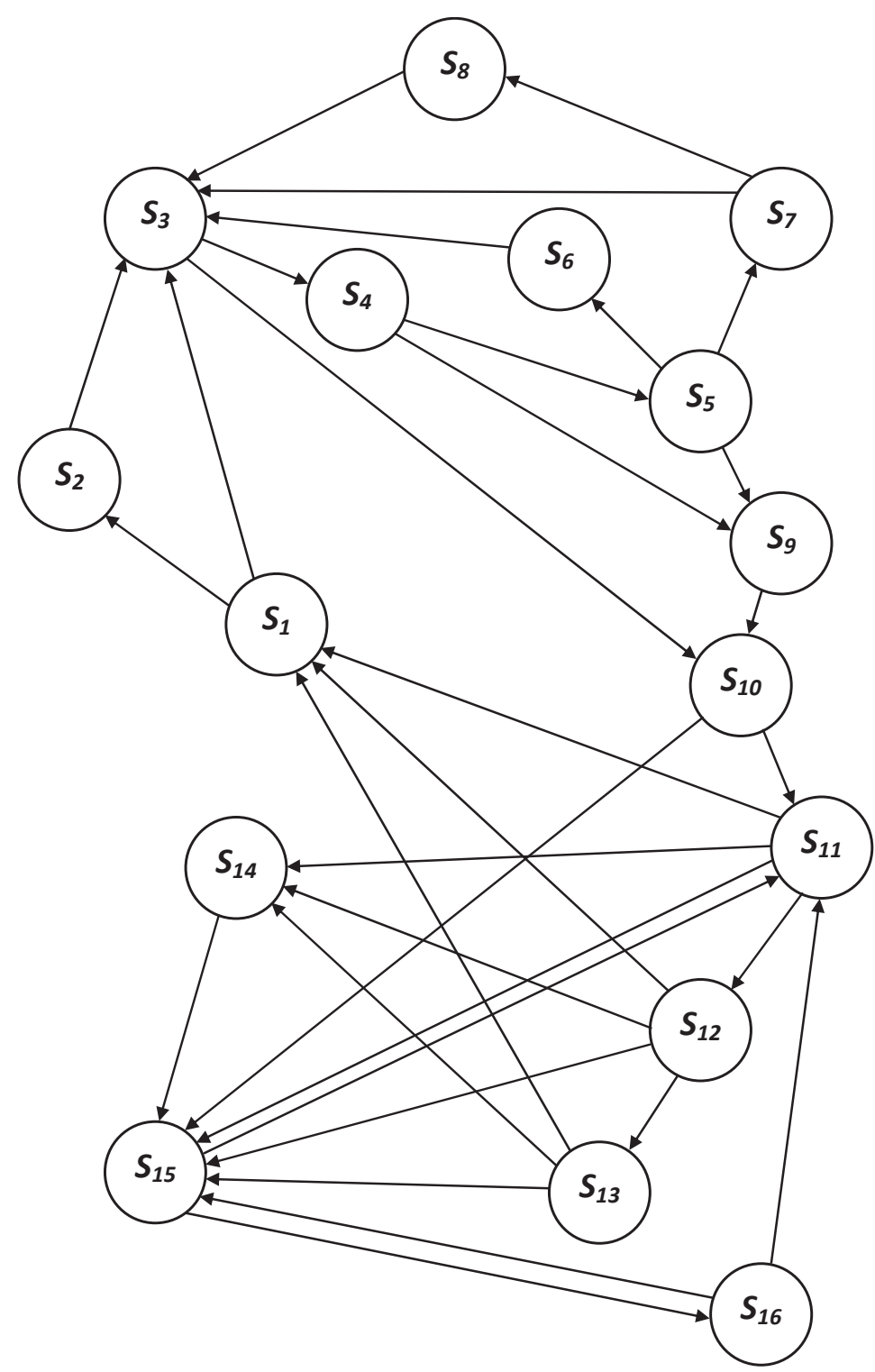

Fig. 1. Directed graph representing the operation and maintenance process of transport means

$$
P=\left[\begin{array}{cccccccccccccccc}
0 & p_{1,2} & p_{1,3} & 0 & 0 & 0 & 0 & 0 & 0 & 0 & 0 & 0 & 0 & 0 & 0 & 0 \\
0 & 0 & p_{2,3} & 0 & 0 & 0 & 0 & 0 & 0 & 0 & 0 & 0 & 0 & 0 & 0 & 0 \\
0 & 0 & 0 & p_{3,4} & 0 & 0 & 0 & 0 & 0 & p_{3,10} & 0 & 0 & 0 & 0 & 0 & 0 \\
0 & 0 & 0 & 0 & p_{4,5} & 0 & 0 & 0 & p_{4,9} & 0 & 0 & 0 & 0 & 0 & 0 & 0 \\
0 & 0 & 0 & 0 & 0 & p_{5,6} & p_{5,7} & 0 & p_{5,9} & 0 & 0 & 0 & 0 & 0 & 0 & 0 \\
0 & 0 & p_{6,3} & 0 & 0 & 0 & 0 & 0 & 0 & 0 & 0 & 0 & 0 & 0 & 0 & 0 \\
0 & 0 & p_{7,3} & 0 & 0 & 0 & 0 & p_{7,8} & 0 & 0 & 0 & 0 & 0 & 0 & 0 & 0 \\
0 & 0 & p_{8,3} & 0 & 0 & 0 & 0 & 0 & 0 & 0 & 0 & 0 & 0 & 0 & 0 & 0 \\
0 & 0 & 0 & 0 & 0 & 0 & 0 & 0 & 0 & p_{9,10} & 0 & 0 & 0 & 0 & 0 & 0 \\
0 & 0 & 0 & 0 & 0 & 0 & 0 & 0 & 0 & 0 & p_{10,11} & 0 & 0 & 0 & p_{10,15} & 0 \\
p_{11,1} & 0 & 0 & 0 & 0 & 0 & 0 & 0 & 0 & 0 & 0 & p_{11,12} & 0 & p_{11,14} & p_{11,15} & 0 \\
p_{12,1} & 0 & 0 & 0 & 0 & 0 & 0 & 0 & 0 & 0 & 0 & 0 & p_{12,13} & p_{12,14} & p_{12,15} & 0 \\
p_{13,1} & 0 & 0 & 0 & 0 & 0 & 0 & 0 & 0 & 0 & 0 & 0 & 0 & p_{13,14} & p_{13,15} & 0 \\
0 & 0 & 0 & 0 & 0 & 0 & 0 & 0 & 0 & 0 & 0 & 0 & 0 & 0 & p_{14,15} & 0 \\
0 & 0 & 0 & 0 & 0 & 0 & 0 & 0 & 0 & 0 & p_{15,11} & 0 & 0 & 0 & 0 & p_{15,16} \\
0 & 0 & 0 & 0 & 0 & 0 & 0 & 0 & 0 & 0 & p_{16,11} & 0 & 0 & 0 & p_{16,15} & 0
\end{array}\right],
$$




$$
\Lambda=\left[\begin{array}{cccccccccccccccc}
-\lambda_{1,1} & \lambda_{1,2} & \lambda_{1,3} & 0 & 0 & 0 & 0 & 0 & 0 & 0 & 0 & 0 & 0 & 0 & 0 & 0 \\
0 & -\lambda_{2,2} & \lambda_{2,3} & 0 & 0 & 0 & 0 & 0 & 0 & 0 & 0 & 0 & 0 & 0 & 0 & 0 \\
0 & 0 & -\lambda_{3,3} & \lambda_{3,4} & 0 & 0 & 0 & 0 & 0 & \lambda_{3,10} & 0 & 0 & 0 & 0 & 0 & 0 \\
0 & 0 & 0 & -\lambda_{4,4} & \lambda_{4,5} & 0 & 0 & 0 & \lambda_{4,9} & 0 & 0 & 0 & 0 & 0 & 0 & 0 \\
0 & 0 & 0 & 0 & -\lambda_{5,5} & \lambda_{5,6} & \lambda_{5,7} & 0 & \lambda_{5,9} & 0 & 0 & 0 & 0 & 0 & 0 & 0 \\
0 & 0 & \lambda_{6,3} & 0 & 0 & -\lambda_{6,6} & 0 & 0 & 0 & 0 & 0 & 0 & 0 & 0 & 0 & 0 \\
0 & 0 & \lambda_{7,3} & 0 & 0 & 0 & -\lambda_{7,7} & \lambda_{7,8} & 0 & 0 & 0 & 0 & 0 & 0 & 0 & 0 \\
0 & 0 & \lambda_{8,3} & 0 & 0 & 0 & 0 & -\lambda_{8,8} & 0 & 0 & 0 & 0 & 0 & 0 & 0 & 0 \\
0 & 0 & 0 & 0 & 0 & 0 & 0 & 0 & -\lambda_{9,9} & \lambda_{9,10} & 0 & 0 & 0 & 0 & 0 & 0 \\
0 & 0 & 0 & 0 & 0 & 0 & 0 & 0 & 0 & -\lambda_{10,10} & \lambda_{10,11} & 0 & 0 & 0 & \lambda_{10,15} & 0 \\
\lambda_{11,1} & 0 & 0 & 0 & 0 & 0 & 0 & 0 & 0 & 0 & -\lambda_{11,11} & \lambda_{11,12} & 0 & \lambda_{11,14} & \lambda_{11,15} & 0 \\
\lambda_{12,1} & 0 & 0 & 0 & 0 & 0 & 0 & 0 & 0 & 0 & 0 & -\lambda_{12,12} & \lambda_{12,13} & \lambda_{12,14} & \lambda_{12,15} & 0 \\
\lambda_{13,1} & 0 & 0 & 0 & 0 & 0 & 0 & 0 & 0 & 0 & 0 & 0 & -\lambda_{13,13} & \lambda_{13,14} & \lambda_{13,15} & 0 \\
0 & 0 & 0 & 0 & 0 & 0 & 0 & 0 & 0 & 0 & 0 & 0 & 0 & -\lambda_{14,14} & \lambda_{14,15} & 0 \\
0 & 0 & 0 & 0 & 0 & 0 & 0 & 0 & 0 & 0 & \lambda_{15,11} & 0 & 0 & 0 & -\lambda_{15,15} & \lambda_{15,16} \\
0 & 0 & 0 & 0 & 0 & 0 & 0 & 0 & 0 & 0 & \lambda_{16,11} & 0 & 0 & 0 & \lambda_{16,15} & -\lambda_{16,16}
\end{array}\right],
$$

where:

$p_{i j}$ - probability of transition from state $S_{i}$ to state $S_{j}$,

$\lambda_{i}$ - intensity of staying in state $S_{i}$ of $X(t)$ process,

$\lambda_{i j}$ - intensity of transition from state $S_{i}$ to state $S_{j}$.

In order to determine boundary probabilities $p_{i}^{*}$ for Markov's process, a system of linear equations was built, on the basis of $\Lambda$ (2) matrixes:

$$
\sum_{i=1}^{16} \lambda_{i j} \cdot p_{i}^{*}=0, \quad j=1,2, \ldots, 16,
$$

whence

$$
\left\{\begin{array}{l}
-\lambda_{1,1} \cdot p_{1}^{*}+\lambda_{11,1} \cdot p_{11}^{*}+\lambda_{12,1} \cdot p_{12}^{*}+\lambda_{13,1} \cdot p_{13}^{*}=0 \\
\lambda_{1,2} \cdot p_{1}^{*}-\lambda_{2,2} \cdot p_{2}^{*}=0 \\
\lambda_{1,3} \cdot p_{1}^{*}+\lambda_{2,3} \cdot p_{2}^{*}-\lambda_{3,3} \cdot p_{3}^{*}+\lambda_{6,3} \cdot p_{6}^{*}+\lambda_{7,3} \cdot p_{7}^{*}+\lambda_{8,3} \cdot p_{8}^{*}=0 \\
\lambda_{3,4} \cdot p_{3}^{*}-\lambda_{4,4} \cdot p_{4}^{*}=0 \\
\lambda_{4,5} \cdot p_{4}^{*}-\lambda_{5,5} \cdot p_{5}^{*}=0 \\
\lambda_{5,6} \cdot p_{5}^{*}-\lambda_{6,6} \cdot p_{6}^{*}=0 \\
\lambda_{5,7} \cdot p_{5}^{*}-\lambda_{7,7} \cdot p_{7}^{*}=0 \\
\lambda_{7,8} \cdot p_{7}^{*}-\lambda_{8,8} \cdot p_{8}^{*}=0 \\
\lambda_{4,9} \cdot p_{4}^{*}+\lambda_{5,9} \cdot p_{5}^{*}-\lambda_{9,9} \cdot p_{9}^{*}=0 \\
\lambda_{3,10} \cdot p_{3}^{*}+\lambda_{9,10} \cdot p_{9}^{*}-\lambda_{10,10} \cdot p_{10}^{*}=0 \\
\lambda_{10,11} \cdot p_{10}^{*}-\lambda_{11,11} \cdot p_{11}^{*}+\lambda_{15,11} \cdot p_{15}^{*}+\lambda_{16,11} \cdot p_{16}^{*}=0 \\
\lambda_{11,12} \cdot p_{11}^{*}-\lambda_{12,12} \cdot p_{12}^{*}=0 \\
\lambda_{12,13} \cdot p_{12}^{*}-\lambda_{13,13} \cdot p_{13}^{*}=0 \\
\lambda_{11,14} \cdot p_{11}^{*}+\lambda_{12,14} \cdot p_{12}^{*}+\lambda_{13,14} \cdot p_{13}^{*}-\lambda_{14,14} \cdot p_{14}^{*}=0 \\
\lambda_{10,15} \cdot p_{10}^{*}+\lambda_{11,15} \cdot p_{11}^{*}+\lambda_{12,15} \cdot p_{12}^{*}+\lambda_{13,15} \cdot p_{13}^{*}+\lambda_{14,15} \cdot p_{14}^{*}-\lambda_{15,15} \cdot p_{15}^{*}+\lambda_{16,15} \cdot p_{16}^{*}=0 \\
\lambda_{15,16} \cdot p_{15}^{*}-\lambda_{16,16} \cdot p_{16}^{*}=0 .
\end{array}\right.
$$




\section{Availability of executive subsystem}

In order to define availability of technical objects (means of transport) based on the Markovian model of operation and maintenance process, the states of the process of technical object should be divided into availability states $S_{G}$ and non-availability states $S_{N G}$ of the object for the carrying out of the assigned task. The states of availability of the technical objects are such states, when the object, including the operator remains in the operational system, is efficient and supplied, or will be repaired and/or supplied in a period of time shorter than the period of the time reserve assigned for the task. Non-availability states are such states, when the object or the operator remain outside of the operational system (efficient or not) as well as when an inefficient and/or unsupplied object remains within the operational system.

Availability of a single technical object defined on the basis of the Markovian model of operation and maintenance process is determined as the sum of limit probabilities $p_{i}^{*}$ of remaining at states belonging to the availability states set $[2,4]$

$$
G^{O T}=\sum_{i} p_{i}^{*} \text { for } S_{i} \in S_{G}, i=1,2, \ldots, 16,
$$

In the presented model, the following technical object availability states were enummerated:

- state $S_{1}$ - awaiting the carrying out of the task at the bus depot parking space,

- state $S_{2}$ - repair at the bus depot parking space without losing a ride,

- state $S_{3}$ - carrying out of the transport task,

- state $S_{6}$ - repair by technical support unit without losing a ride,

- state $S_{8}$ - awaiting the start of task realization after technical support repair.

Then, with the use of the MATHEMATICA software, the limit probability $p_{i}^{*}$ of staying in states of Markov process and the availability of technical objects of the transport system were determined:

$$
G^{O T}=p_{1}^{*}+p_{2}^{*}+p_{3}^{*}+p_{6}^{*}+p_{8}^{*} .
$$

In the tested transport system the individual technical object (means of transport) are linked by a threshold structure of the $k$ of $N$ type, where $k$ marks the required number of technical objects available for the carrying out of the assigned transport task, while $N$ the number of all technical objects used in the system. Then the availability of the executive subsystem with a threshold structureis marked by the relation [7]:

$$
G^{P W}=\sum_{i=k}^{N}\left(\begin{array}{c}
N \\
i
\end{array}\right) \cdot\left(G^{O T}\right)^{i^{i}} \cdot\left(1-G^{O T}\right)^{N-i} .
$$

\section{The criteria of evaluating the availability of executive subsystem}

In the presented method the evaluation of executive subsystem, is done on the basis of the comparison of its value and the value of the required availability, which the executive subsystem should have for the assigned task to be carried out correctly. The required availability of the executive subsystem for the realization of the assigned transport task is determined depending on the required minimum number of available technical objects $k_{w}$, defined in the description of the assigned transport task as well as the number of all technical objects used in the transport system $N$, according to the following formula

$$
G_{w}^{P W}=\frac{T_{w}^{P W}}{T_{w}^{P W}+U_{w}^{P W}}=\frac{k_{w} \cdot \tau_{z}}{k_{w} \cdot \tau_{z}+n_{w} \cdot \tau_{z}}=\frac{k_{w}}{k_{w}+n_{w}}=\frac{k_{w}}{N},
$$

where for the given assigned transport task:

$T_{w}^{P W}$ - required time of availability of the executive subsystem,

$U_{w}^{P W}$ - required time of non-availability time of the executive subsystem, 
$k_{w} \quad-$ the required minimum number of available technical objects,

$n_{w} \quad$ - the required maximum number of non-available technical objects,

$N$ - the number of all technical objects used in the transport system,

$\tau_{z} \quad$ - required time for the realization of the assigned transport task.

In order to assure the correct realization of the assigned transport task it is necessary for the value of the availability of the executive subsystem $G^{P W}$ to be at least equal to the value of required availability $G_{w}^{P W}\left(G^{P W} \geq G_{w}^{P W}\right)$. Taking into consideration the fact that the required minimum number of objects available for the particular transport task is constant $\left(k_{w}=\right.$ const), the availability of the executive subsystem $G^{P W}$ depends on the number $N$ of technical objects used in the system as well as the availability of a single technical object $G^{O T}$. Then for the evaluation of the availability of the executive subsystem for the realization of the assigned task the following criteria were adopted:

- facilitating the definition of a required value of availability of a single technical object $G_{w}^{O T}$ for a given number of technical objects used in the transport system $N$ :

$$
\begin{gathered}
G^{O T}=G_{w}^{O T} \Leftrightarrow G^{P W} \geq G_{w}^{P W}, \\
G^{O T}=G_{w}^{O T} \Leftrightarrow \sum_{i=k_{w}}^{N}\left(\begin{array}{c}
N \\
i
\end{array}\right) \cdot\left(G^{O T}\right)^{i} \cdot\left(1-G^{O T}\right)^{N-i} \geq \frac{k_{w}}{N},
\end{gathered}
$$

- facilitating the definition of the required number of technical objects used in the transport system $N_{w}$ for a given value of the availability of a single technical object $G^{O T}$ :

$$
\begin{gathered}
N=N_{w} \Leftrightarrow G^{P W} \geq G_{w}^{P W}, \\
N=N_{w} \Leftrightarrow \sum_{i=k_{w}}^{N}\left(\begin{array}{c}
N \\
i
\end{array}\right) \cdot\left(G^{O T}\right)^{i} \cdot\left(1-G^{O T}\right)^{N-i} \geq \frac{k_{w}}{N} .
\end{gathered}
$$

\section{Results}

Based on the source data obtained from operational research carried out in an existing municipal bus transport system, the values of the elements of matrix $P(1)$ and matrix $\Lambda$ (2), the values of border probabilities for remaining process states $p_{i}^{*}$, availability of a single technical object $G^{O T}$, actual availability $G^{P W}$ and required availability of the executive subsystem $G_{w}^{P W}$. Then for the value of parameters describing assigned to the executive subsystem transport tasks, using the dependency of presented models from (5) to (12), the graphs are drown $G^{P W}=f\left(G^{O T}, N\right), G^{P W}=f\left(k_{w}, N\right)$, $G_{w}^{O T}=f\left(G^{P W}\right)$ and $N_{w}=f\left(G^{P W}\right)$. Sample results are presented in Fig. 2-5.

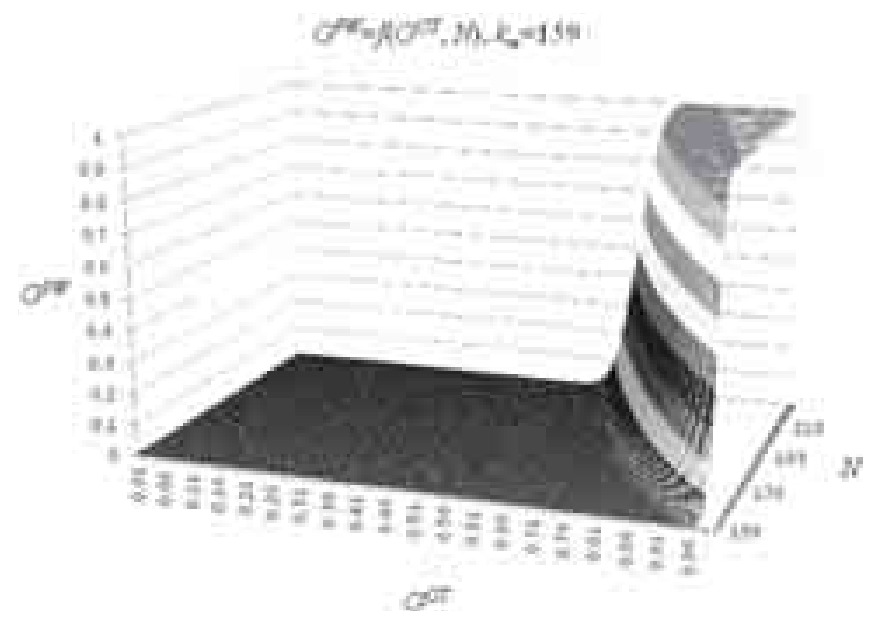

Fig. 2. Availability of the executive subsystem $G^{P W}$ in the function of availability of a single technical object $G^{O T}$ and the number of the used object in the $N$ system, for given object number, realized the assigned transport task $k_{w}$ 


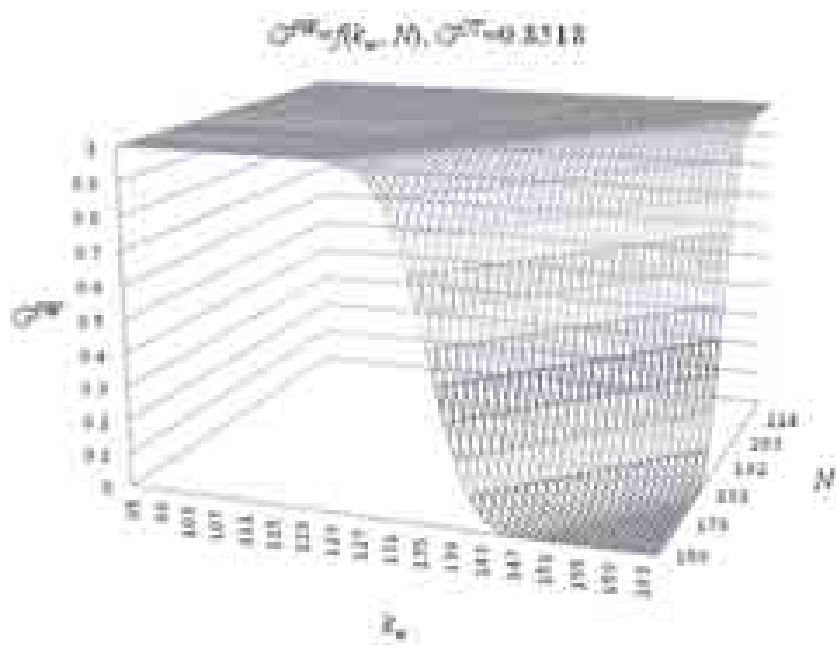

Fig. 3. Availability of the executive subsystem $G^{P W}$ in the function of the number of technical objects realized the assigned transport task $k_{w}$ and of all objects used in the system $N$, for given availability of a single object $G^{O T}$

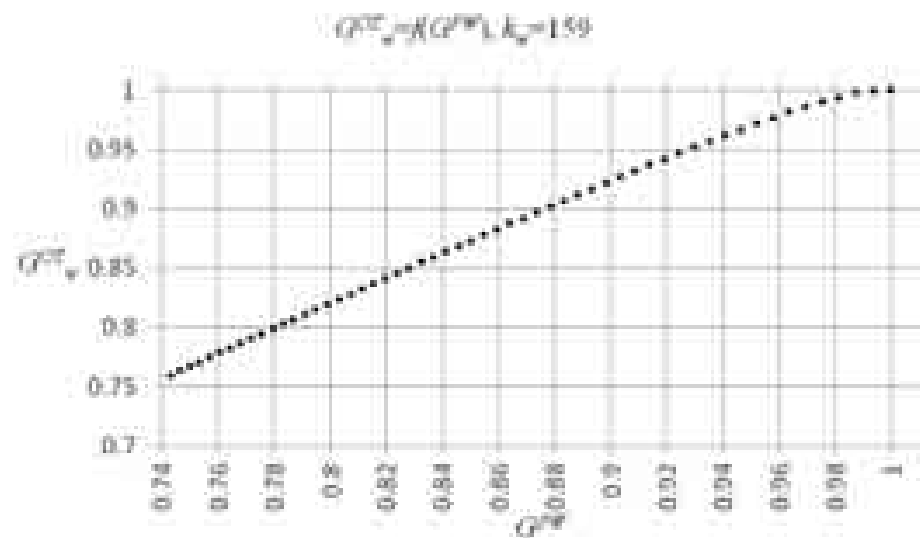

Fig. 4. Required availability of technical object $G_{w}^{O T}$ depending on the value of $G^{P W}$ and $k_{w}$

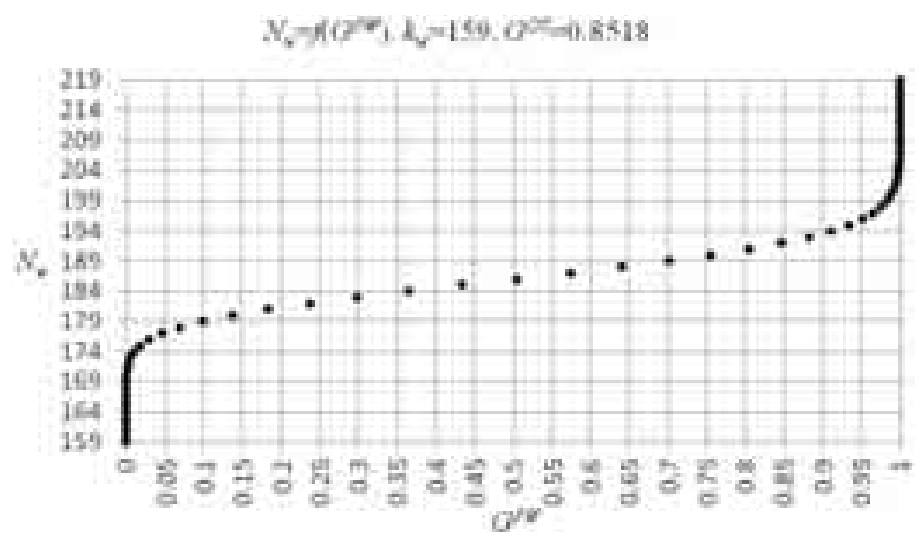

Fig. 5. Required number of the technical objects used in the system of transport $N_{w}$ in the function of availability of the executive subsystem $G^{P W}$, for given value $k_{w}$ and $G^{O T}$

On the basis of the graphs drawn, it is possible to determine:

1. required availability $G_{w}^{O T}$ technical objects (means of transport) used in the system, depending on the number $k_{w}$ objects, that should to realize the assigned transport tasks and the number of all technical objects used in the system $N$,

2. required number $N_{w}$ objects in the system, depending on the number $k_{w}$ objects, that should to realize the assigned transport tasks and actual availability $G^{O T}$ technical objects (means of transport) used in the system. 
The presented method enables the selection, as well as the required availability $G_{w}^{O T}$ and the required number $N_{w}$ of technical objects (means of transport) used in the analyzed system, so that value of actual availability $G^{P W}$ of the executive subsystem is at least equal the required availability value $G_{w}^{P W}$ for the correct realization of the assigned transport tasks in given conditions.

\section{References}

[1] Cinlar, E., Introduction to Stochastic Processes, Prentice Hall, New-Jersey 1975.

[2] Grabski, F., Jaźwiński, J., Funkcje o losowych argumentach w zagadnieniach niezawodności, bezpieczeństwa i logistyki, WKiŁ, Warszawa 2009.

[3] Iosifescu, M., Skończone procesy Markowa i ich zastosowanie, PWN, Warszawa 1988.

[4] Jaźwiński, J., Grabski, F., Niektóre problemy modelowania systemów transportowych, Instytut Technologii Eksploatacji, Warszawa-Radom 2003.

[5] Kowalenko, I. N., Kuzniecow, N. J., Szurienkow, W. M., Procesy stochastyczne. Poradnik, PWN, Warszawa 1989.

[6] Kulkarni, V. G., Modeling and Analysis of Stochastic Systems, Chapman \& Hall, New York 1995.

[7] Praca zbiorowa pod redakcją J. M. Migdalskiego, Inżynieria niezawodności. Poradnik, Wydawnictwo ZETOM, Warszawa 1992.

[8] Woropay, M., Migawa, K., Markov Model of the Operational Use Process in an Autonomous System, Polish Journal of Environmental Studies, Vol. 16, No. 4A, 2007.

[9] Żurek, J., Problemy gotowości techniki lotniczej, Rozdział 13, Praca zbiorowa, Problemy badań i eksploatacji techniki lotniczej, Tom 2, Wydawnictwo ITWL, Warszawa 1993. 